\title{
The genome of Romanomermis culicivorax: revealing fundamental changes in the core developmental genetic toolkit in Nematoda
}

\author{
Philipp H Schiffer ${ }^{1 *}$, Michael Kroiher ${ }^{1}$, Christopher Kraus ${ }^{1}$, Georgios D Koutsovoulos ${ }^{2}$, Sujai Kumar ${ }^{2}$, \\ Julia I R Camps ${ }^{1}$, Ndifon A Nsah ${ }^{1}$, Dominik Stappert ${ }^{3}$, Krystalynne Morris ${ }^{4}$, Peter Heger ${ }^{1}$, \\ Janine Altmüller ${ }^{5}$, Peter Frommolt ${ }^{5}$, Peter Nürnberg ${ }^{5}$, W Kelley Thomas ${ }^{4}$, Mark L Blaxter ${ }^{2}$ \\ and Einhard Schierenberg ${ }^{1}$
}

\begin{abstract}
Background: The genetics of development in the nematode Caenorhabditis elegans has been described in exquisite detail. The phylum Nematoda has two classes: Chromadorea (which includes C. elegans) and the Enoplea. While the development of many chromadorean species resembles closely that of C. elegans, enoplean nematodes show markedly different patterns of early cell division and cell fate assignment. Embryogenesis of the enoplean Romanomermis culicivorax has been studied in detail, but the genetic circuitry underpinning development in this species has not been explored.

Results: We generated a draft genome for $R$. culicivorax and compared its gene content with that of $C$. elegans, a second enoplean, the vertebrate parasite Trichinella spiralis, and a representative arthropod, Tribolium castaneum. This comparison revealed that $R$. culicivorax has retained components of the conserved ecdysozoan developmental gene toolkit lost in C. elegans. T. spiralis has independently lost even more of this toolkit than has C. elegans. However, the C. elegans toolkit is not simply depauperate, as many novel genes essential for embryogenesis in C. elegans are not found in, or have only extremely divergent homologues in R. culicivorax and T. spiralis. Our data imply fundamental differences in the genetic programmes not only for early cell specification but also others such as vulva formation and sex determination.
\end{abstract}

Conclusions: Despite the apparent morphological conservatism, major differences in the molecular logic of development have evolved within the phylum Nematoda. R. culicivorax serves as a tractable system to contrast C. elegans and understand how divergent genomic and thus regulatory backgrounds nevertheless generate a conserved phenotype. The R. culicivorax draft genome will promote use of this species as a research model.

Keywords: Nematode, Genome, Evolution, Development, Caenorhabditis, Mermithida, Romanomermis

\section{Background}

Nematodes have a generally conserved body plan. Their typical form is dictated by the presence of a singlechamber hydroskeleton, where longitudinal muscles act against an inextensible extracellular cuticle. The conservation of organ systems between nematode species is even

\footnotetext{
*Correspondence: philipp.schiffer@googlemail.com

${ }^{1}$ Zoologisches Institut, Universität zu Köln, Cologne, NRW, Germany, ORCiD:0000-0001-6776-0934

Full list of author information is available at the end of the article
}

more striking, with, for example, the nervous system, the somatic gonad and the vulva having very similar general organisations and cellular morphologies across the phylum. It might be thought that these similarities arise from highly stereotypical developmental programmes, but comparative studies challenge this "all nematodes are equal" view.

Embryonic development of the nematode Caenorhabditis elegans has become a paradigmatic model for studying developmental processes in animals, including early soma-germline separation, fate specification including 
inductive interactions, and tissue-specific differentiation. The particular mode of development of C. elegans is distinct within the major metazoan model organisms, but much of the regulatory logic of its development is comparable to that observed in other phyla. One key aspect in which $C$. elegans differs from vertebrate and arthropod models is that $C$. elegans shows a strictly determined development [1], with a largely invariant cell-lineage giving rise to predictable sets of differentiated cells [2]. Inductive cell-cell interactions are, nevertheless, essential for its correct development [1]. C. elegans is a rhabditid nematode, one of approximately 23,000 described and 1 million estimated nematode species. Molecular and morphological systematics of the phylum Nematoda identify two classes: Chromadorea (including Rhabditida, and thus C. elegans), and Enoplea (subdivided into Dorylaimia and Enoplia) $[3,4]$ (Figure 1). C. elegans is a chromadorean, and most investigation of developmental biology of nematodes has been carried out on Chromadorean species. The first description of the early embryonic cell-lineage of a nematode, that of Ascaris (Spirurina within Chromadorea) in the 1880's [5,6], conforms to the C. elegans model. Early development across all suborders of the Rhabditida is very similar $[7,8]$. In general, only minor variations of the division pattern observed in C. elegans

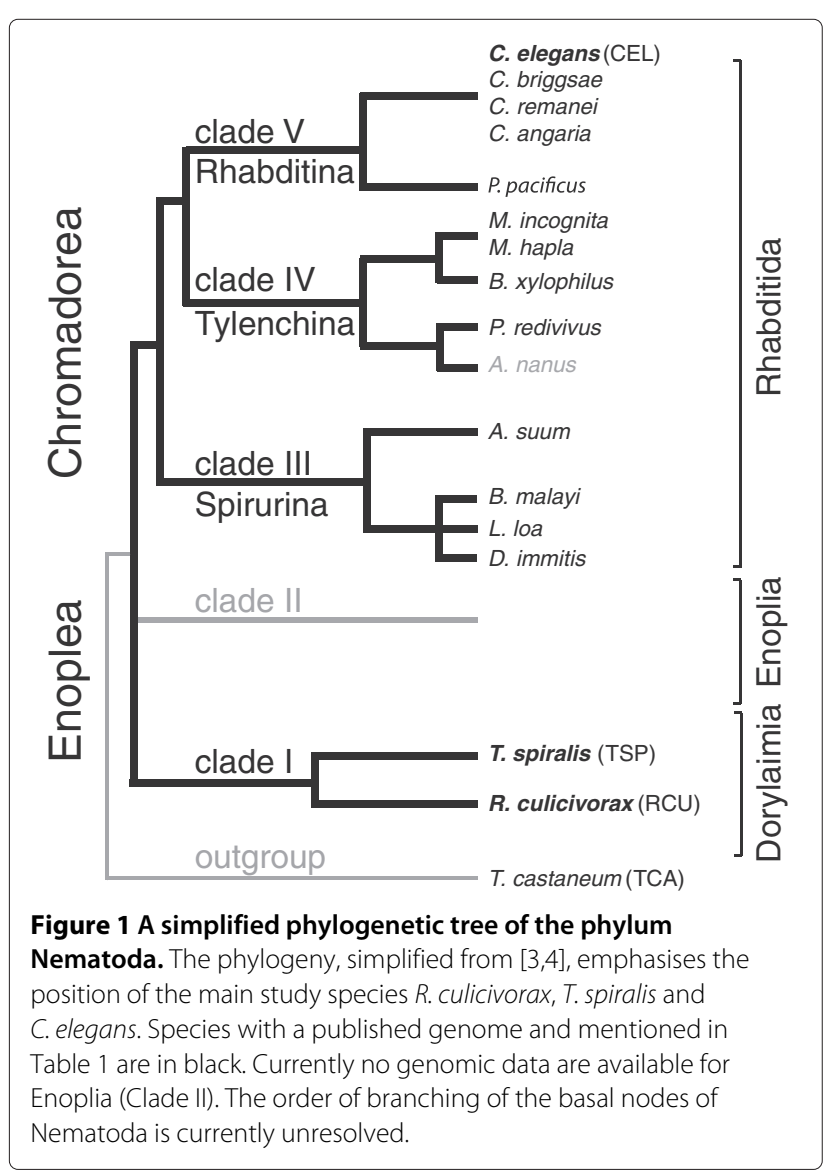

have been described in these nematodes $[9,10]$, including heterochrony in the timing of cell divisions, and restrictions in cell-cell interaction due to different placement of blastomeres in the developing embryo. From these observations it might be assumed that all nematodes follow a C. elegans-like pattern of development. However, deviations from the $C$. elegans pattern observed in other rhabditid nematodes show that the strictly determined mode of development is subject to evolutionary change, making it particularly attractive for the study of underpinning regulatory logic of developmental mechanisms. Indeed, a greater role for regulative interactions in early development has been demonstrated in another rhabditid, Acrobeloides nanus (Tylenchina) [11,12].

Regulative development is common among Metazoa, and is also observed in other Ecdysozoa, including Arthropoda. Indeed, in several enoplean species, early embryos have been found to not display polarised early divisions, arguing against a strongly determined mode of development in this group $[13,14]$. The determined mode found in C. elegans is thus likely to be derived even within Nematoda [15], implying that the core developmental system in Nematoda has changed, while maintaining a very similar organismal output. This phenomenon, termed "developmental system drift" [16], reveals independent selection on the developmental mechanism and the final form produced.

To explore the genetics of development of enoplean and other non-rhabditid nematodes requires tractable experimental systems with a suitable set of methodological tools and extensive genomic data. While $C$. elegans and its embryos are relatively easily manipulated and observed, and the $C$. elegans genome has been fully sequenced [17], embryos from the Enoplia and Dorylaimia are much harder to culture and manipulate. Few viable laboratory cultures exist and obtaining large numbers of embryos from wild material is difficult. Functional molecular analysis of most nematodes, in particular Enoplea, is further hindered by the lack of genetic tools such as mutant analysis or gene-knockdown via RNAi. Performing detailed comparative experimental embryology on a phylogenetically representative set of species across the phylum Nematoda thus remains a distant goal.

The genetic toolkit utilised by a species is represented in its genome, and direct assessment of the genetic capabilities of an organism can thus be assessed through analysis of genome data. Using the background knowledge of pathways and modules used in other taxa, the underpinning logic of a species' developmental system can be inferred from its genome, and the developmental toolkits of different species can be compared. These comparisons can reveal changes in developmental logic between taxa by identifying gene losses during evolution that must result in changed pathway functioning, and similarly identify 
genes recruited to developmental regulatory roles in particular lineages.

Efficient generation of genomic resources for nonmodel species, and the inference of developmental regulatory pathways from the encoded gene sets, is now possible. The majority of the fifteen nematode genomes published to date have been from Rhabditida (Figure 1) [18-26]. The single enoplean genome sequences is from the mammalian parasite Trichinella spiralis (Dorylaimia; order Trichocephalida) [27]. T. spiralis is ovoviviparous, proper development requires intrauterine environment, and early blastomeres are extremely transparent [28] such that individual nuclei are hard to identify (E.S., unpublished observations). Hence, this species is of very limited value for light microscopical image analysis and experimental investigation correlating cell dynamics with the molecular circuitry regulating early development.

Although the genomes of many additional nematode species are being sequenced [29,30], even in this wider sampling of the phylum, Enoplea remains neglected. The enoplean Romanomermis culicivorax (order Mermithida within Dorylaimia) has been established in culture for decades. It infects and kills the larvae of many different mosquito species [31], and is being investigated for its potential as a biocontrol agent of malaria and other disease vectors [31,32]. R. culicivorax and T. spiralis differ fundamentally in many life-cycle and phenotypic characters. $R$. culicivorax reproduces sexually. A single female can produce more than a thousand eggs, and embryos are easily studied under laboratory conditions. They display a developmental pattern that differs markedly from C. elegans. As in other Enoplea [14,33] the first division is equal, and not asymmetric as in $C$. elegans. $R$. culicivorax also shows an inversion of dorso-ventral axis polarity compared to $C$. elegans, while a predominantly monoclonal fate distribution indicates fewer modifying inductions between blastomeres [33,34]. Generation of the hypodermis involves repetitive cell elements extending from posterior to anterior over the remainder of the embryo, a process distinct from that observed in C. elegans [34].

We here catalogue the $R$. culicivorax developmental toolkit derived from annotation of a draft genome sequence. We contrast genes and proteins identified in $R$. culicivorax and T. spiralis with those of C. elegans, and other Ecdysozoa, represented by the arthropod Tribolium castaneum. We conclude that major changes in the regulatory logic of development have taken place during nematode evolution, possibly as a consequence of developmental system drift, and that the model species C. elegans is considerably derived compared to an ecdysozoan (and possibly metazoan) ground system. However, we are still able to define conserved gene sets that may act in "phylotypic" developmental stages.

\section{Results and discussion}

Romanomermis culicivorax has a large and repetitive genome

A draft genome assembly for $R$. culicivorax was generated from 26.9 gigabases (Gb) of raw data (filtered from a total of $41 \mathrm{~Gb}$ sequenced; Additional file 1: Table S1). The assembly has a contig span of 267 million base pairs (Mb) and a scaffold span of $323 \mathrm{Mb}$. The $52 \mathrm{Mb}$ of spanned gaps are likely inflated estimates derived from use of the SSPACE scaffolder. We do not currently have a validated independent estimate of genome size for $R$. culicivorax, but preliminary measurements with Feulgen densitometry suggest a size greater than $320 \mathrm{Mb}$ (Elizabeth Martínez Salazar pers. comm.). The $R$. culicivorax genome is thus three times bigger than that of $C$. elegans, and five times that of T. spiralis (Table 1). The assembly is currently in 62,537 scaffolds and contigs larger than $500 \mathrm{bp}$, with an N50 of 17.6 kilobases (kb). The N50 for scaffolds larger than $10 \mathrm{~kb}$ is $29.9 \mathrm{~kb}$, and the largest scaffold is over $200 \mathrm{~kb}$. The GC content is $36 \%$, comparable to $38 \%$ of C. elegans and $34 \%$ in T. spiralis. We identified $47 \%$ of the $R$. culicivorax genome as repetitive. To validate this estimate we applied our repeat-finding approach to previously published genomes and achieved good accordance with these data (Table 1). The non-repetitive content of the $R$. culicivorax genome is thus approximately twice that of $C$. elegans and three times that of T. spiralis. T. spiralis thus stands out as having the least complex nematode genome sequenced so far, and the contrast with $R$. culicivorax indicates that small genomes are not characteristic of Dorylaimia.

We generated 454 Sequencing transcriptome data from mixed adults, and assembled 29,095 isotigs in 22,418 isogroups, spanning $23 \mathrm{Mb}$. These are likely to be a reasonable estimate of the $R$. culicivorax transcriptome. Using BLAT [35], 21,204 of the isotigs were found to be present (with matches covering $>80 \%$ of the isotig) in single contigs or scaffolds of the genome assembly, suggesting reasonable biological completeness and contiguity of the genome. We also used the CEGMA [36] approach to assess quality of the genome assembly, and found a high representation (90\% partial, $75 \%$ complete) and a low proportion of duplicates (1.1 fold) (Table 2). Automated gene prediction with iterative rounds of the MAKER pipeline [37], using the transcriptome data as evidence both directly and through GenomeThreaderderived mapping, yielded a total of nearly 50,000 gene models. These were reduced to 48,171 by merging those with identities $>99 \%$ using Cd-hit [38]. Within the 48,171 models, 12,026 were derived from the AUGUSTUS modeller [39] and 36,145 from SNAP. Because AUGUSTUS predictions conservatively require some external evidence (transcript mapping and/or sequence similarity to other known proteins), we regarded these as the most reliable 
Table 1 Genome statistics

\begin{tabular}{|c|c|c|c|c|c|c|}
\hline Species & $\begin{array}{l}\text { Approximate } \\
\text { genome size }\end{array}$ & $\begin{array}{l}\text { Estimated } \\
\text { repeat content }\end{array}$ & $\begin{array}{l}\text { Median }{ }^{\dagger} \\
\text { exon length }\end{array}$ & $\begin{array}{l}\text { Median }^{\dagger} \\
\text { intron length }\end{array}$ & $\begin{array}{l}\text { GC } \\
\text { content }\end{array}$ & Source \\
\hline C.elegans & $100 \mathrm{Mb}$ & $17 \%(16.5 \%)$ & $145 \mathrm{bp}$ & $69 \mathrm{bp}$ & $38 \%$ & {$[17,18]$} \\
\hline P. pacificus & $165 \mathrm{Mb}$ & $15.3 \%(17 \%)$ & $85 \mathrm{bp}$ & $141 \mathrm{bp}$ & $42 \%$ & {$[20,25]$} \\
\hline A. suum & $334 \mathrm{Mb}$ & $4.4 \%$ & $144 \mathrm{bp}$ & $907 \mathrm{bp}$ & $37.9 \%$ & {$[21,40]$} \\
\hline B. malayi & $95 \mathrm{Mb}$ & $16.5 \%(15 \%)$ & $140 \mathrm{bp}$ & $219 b p$ & $30 \%$ & [22] \\
\hline B. xylophilus & $69 \mathrm{Mb}$ & $22,5 \%$ & $183 b p$ & $69 b p$ & $40 \%$ & [25] \\
\hline M. incognita & $\sim 200 \mathrm{Mb}$ & $36,7 \%$ & $136 \mathrm{bp}$ & $82 \mathrm{bp}$ & $31 \%$ & [24] \\
\hline T. spiralis & $63 \mathrm{Mb}$ & $19.8 \%(18 \%)$ & $128 \mathrm{bp}$ & $283 \mathrm{bp}$ & $34 \%$ & {$[27]$} \\
\hline R. culicivorax & $>270 \mathrm{Mb}$ & $48.2 \%$ & $161 \mathrm{bp}$ & $405 b p$ & $36 \%$ & this work \\
\hline
\end{tabular}

Repeat content of different nematode genomes appears not to be directly correlated with genome size. Re-calculation in selected genomes shows little deviance from published data (in parentheses)* and thus indicates the validity of our inference for $R$. culicivorax.

*For B. xylophilus and $M$. incognita only reference data is given as the same programs were used for initial inference (see references); $A$. suum not re-calculated.

${ }^{\#}$ M. incognita genome size given as $86 \mathrm{Mbp}$ in [24] has been re-estimated to about $150 \mathrm{Mbp}$ (E. Danchin pers. comm.).

'Median lengths for A. suum and T. spiralis were calculated in this work as these data are not given in the cited publications.

and biologically complete. In comparison $C$. elegans has $\sim 22,000$ genes, and T. spiralis has $\sim 16,000$. The satellite model nematode Pristionchus pacificus has $\sim 27,000$ genes [20]. Exons of the AUGUSTUS-predicted genes in R. culicivorax had a median length of $161 \mathrm{bp}$, slightly larger than those in C. elegans (137bp) and T. spiralis (128bp). Introns of the $R$. culicivorax AUGUSTUS models, with a median of $405 \mathrm{bp}$, were much larger than those of $C$. elegans

Table 2 Assembly and annotation statistics

\begin{tabular}{lc}
\hline Metric & Result \\
\hline Contigs > 100bp span & $267,342,457 \mathrm{bp}$ \\
\hline Scaffolds >500bp span & $322,765,761 \mathrm{bp}$ \\
\hline Num. contigs/scaffolds & 62,537 \\
\hline N50 contigs/scaffolds $>500 \mathrm{bp}$ & $17,632 \mathrm{bp}$ \\
\hline N50 scaffolds $>500 \mathrm{bp}$ & $29,995 \mathrm{bp}$ \\
\hline Max contig length & $28,847 \mathrm{bp}$ \\
\hline Max scaffold length & $201,054 \mathrm{bp}$ \\
\hline Mean transcript length & $593 \mathrm{bp}$ \\
\hline Mean protein length & $190 \mathrm{aa}$ \\
\hline MAKER AUGUSTUS predictions & $12,026 \mathrm{proteins}$ \\
\hline MAKER SNAP predictions & 36,145 proteins \\
\hline Num. ESTs (isogroups) & $22,418 \mathrm{ESTs}$ \\
\hline Mean EST length & $330 \mathrm{bp}$ \\
\hline 80\% BLAT sequence coverage & $21,204 \mathrm{ESTs}$ \\
\hline CEGMA compl. completeness & $75.40 \%$ \\
\hline CEGMA Group 1 part. compl. & $81.82 \%$ \\
\hline CEGMA Group 2 part. compl. & $91.07 \%$ \\
\hline CEGMA Group 3 part. compl. & $91.80 \%$ \\
\hline CEGMA Group 4 part. compl. & $95.38 \%$ \\
\hline
\end{tabular}

(69 bp) or T. spiralis (283bp). The small introns observed in C. elegans and other rhabditid nematodes (Table 2) are thus likely to be a derived feature.

We annotated 1,443 tRNAs in the $R$. culicivorax genome using INFERNAL [41] and tRNAscan-SE [42], of which 382 were pseudogenes (see Additional file 1: Table S2 for details). In comparison, T. spiralis has 134 tRNAs of which 7 are pseudogenes, while C. elegans has 606 tRNAs with 36 pseudogenes [43]. Threonine (Thr) tRNAs were particularly overrepresented (676 copies), a finding echoed in the genomes of Meloidogyne incognita and Meloidogyne floridensis $[24,43]$ and in P. pacificus [20]. The latter has also an overrepresentation of Arginine tRNAs [43].

We have made available the annotated $R$. culicivorax genome, with functional categorisations of predicted genes and proteins and annotation features, in a dedicated genome browser at http://romanomermis.nematod.es.

\section{The R.culicivorax gene set is more representative of Dorylaimia than $T$. spiralis}

The phylogenetic placement of $R$. culicivorax makes its genome attractive for exploring the likely genetic complexity of an ancestral nematode. With T. spiralis, it can be used to reveal the idiosyncrasies of the several genomes available for Rhabditida. To polarise this comparison, we used the arthropod Tribolium castaneum, for which a high quality genome sequence is available [44]. T. castaneum development is considered less derived than that of the major arthropod model Drosophila melanogaster [45]. The OrthoMCL pipeline accurately clusters orthologous proteins, facilitating the complex task of grouping proteins that are likely to share biological function in divergent organisms [46], and performs better than approaches that simply use domain presence information or aggregative approaches such as psiBLAST [47]. We used the 
OrthoMCL pipeline to generate a set of protein clusters for the four species ( $R$. culicivorax, T. spiralis, C. elegans and $T$. castaneum). While the large divergence between these species may obscure relationships between protein sequences, making inference of orthology problematic [48-50], the parameters used were most inclusive [50-52]. Additionally, as the $R$. culicivorax genome assembly may not be complete we based inference of absence on shared loss in both R. culicivorax and T. spiralis. Additionally, we validated inferences of absence from the OrthoMCL analyses by performing detailed sequence comparisons using BLAST + [53] (Additional file 2).

We identified 3,274 clusters that contained protein representatives from all three nematodes, and 2,833 of these also contained at least one $T$. castaneum representative (Figure 2). These 2,833 clusters represent a conserved ecdysozoan (and possibly metazoan) core proteome. Many clusters had T. castaneum members, and members from some but not all of the three nematodes, representing candidate examples of loss in one or more nematode lineages of ancient proteins. For example, we identified clusters containing proteins from only one of the nematode species. T. spiralis had the lowest number of these (975), while $C$. elegans and $R$. culicivorax each had over two thousand. Interestingly, of the 2,747 clusters with only $R$. culicivorax proteins from Nematoda, 324 included T. castaneum orthologues, wheras C. elegans only shared 283 clusters uniquely with the beetle. T. spiralis has lost more of these phylogenetically ancient genes than has either $R$. culicivorax or $C$. elegans. T. spiralis and $C$. elegans shared only 412 clusters exclusive of $R$. culicivorax members, while $R$. culicivorax and $C$. elegans shared about 1300 clusters exclusive of T. spiralis. Despite their phylogenetic affinity, $R$. culicivorax

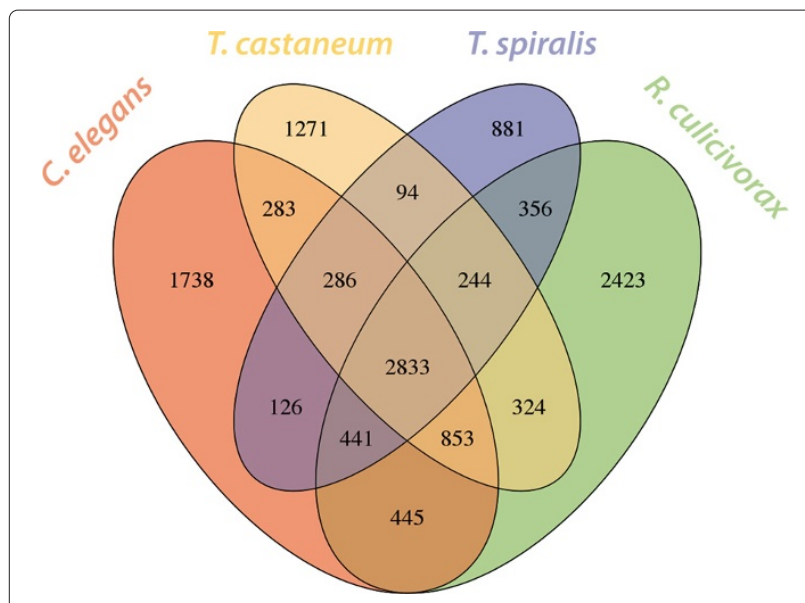

Figure 2 Clusters of homologous proteins. Shared and species-unique clusters of homologous proteins from a comparison of the proteomes of Romanomermis culicivorax, Trichinella spiralis, Caenorhabditis elegans and Tribolium castaneum using OrthoMCL. and T. spiralis only shared 600 clusters exclusive of $C$. elegans (Figure 2). We suggest that T. spiralis genome is not typical of dorylaims. In comparison to other nematodes it is smaller, has fewer genes overall, and has fewer phylogenetically ancient genes. This is congruent with the previously reported loss of proteins with metabolic function in T. spiralis [27]. This reduction in genetic complexity could be due to evolutionary pressures following acquisition of a lifestyle that lacks a free-living stage. Many parasitic and endosymbiotic prokaryotes and eukaryotes have reduced genome sizes, though this is not an absolute rule [54].

Clusters containing only $R$. culicivorax and T. spiralis proteins might identify functions distinct to these dorylaim nematodes. In the $461 \mathrm{~T}$. spiralis and $806 \mathrm{R}$. culicivorax proteins in these clusters, a total of 65 GO terms were found to be overrepresented (single test $\mathrm{p}<0.05$ by Fisher's exact test). While $C$. elegans has a reduced ability to methylate DNA [55], we found four methylationassociated GO terms among the 64 overrepresented. We also detected significant enrichment (single test $\mathrm{p}<0.05$ ) for GO terms describing chromatin and DNA methylation functions in the set of $R$. culicivorax proteins that lacked homologues in C. elegans (see Additional file 3). Important roles for methylation and changes in methylation patterns during $T$. spiralis development have been inferred from transcriptional profiling [56]. Methylation is important for the silencing of transposable elements $[57,58]$ and could play a crucial role in the highly repetitive $R$. culicivorax genome.

The clusters that contained $R$. culicivorax, T. spiralis and $T$. castaneum proteins but no $C$. elegans orthologues might contain proteins involved in core ecdysozoan processes lost in C. elegans. In these clusters we identified 40 GO terms overrepresented (single test $\mathrm{p}<0.05$ ) compared to the C. elegans proteome (see Additional file 3). Some of these GO terms were linked to chromatin remodelling and methylation (e.g. Ino80 complex, histone arginine methylation). Other overrepresented GO terms were related to cell signalling (the Wnt receptor pathway; the C. elegans Wnt signalling system is distinct from other metazoa [59]), and ecdysone receptor holocomplex (potentially a basic ecdysozoan function [60]).

\section{The genetic background of development in $R$. culicivorax and $T$. spiralis differs markedly from that of $C$. elegans} In a recent multi-species developmental time course expression analysis within several Caenorhabditis species, conserved sets of genes were found to have conserved patterns of differential expression in discrete phases in the timeline from zygote to the hatching larva [61].

Nearly half (845) of these 1725 conserved, differentially expressed $C$. elegans proteins were not clustered with $R$. culicivorax or T. spiralis proteins using OrthoMCL. We 
were unable to identify any sequence similarity for 450 of these C. elegans proteins, while 395 had only marginal similarities insufficent for OrthoMCL clustering. Eighteen of these 395 are members of C. elegans nuclear hormone receptor subfamilies, 5 are innexin type gapjunction proteins, 6 are TWiK potassium channel proteins and 5 are acetylcholine receptor proteins. These protein families are particularly diverse and expanded in C. elegans [62-65] and we suggest that they represent rapidly evolved, divergent duplications within the lineage leading to C. elegans. The proportion of Caenorhabditis-restricted genes across the developmental time course examined by Levin et al. [61] varied from $36 \%$ to $60 \%$ (Figure 3 and Additional file 4). Thus a surprisingly high proportion of Caenorhabditis genes with conserved expression during embryogenesis appear to be unique to the genus or are so divergent that we could not detect possible orthologues in the dorylaims. The pattern of higher retention of conserved genes in $R$. culicivorax compared to $T$. spiralis was also evident in these conserved-expression developmental genes, as 238 had $R$. culicivorax orthologues but lacked a T. spiralis orthologues. Given the conservatism of body plan evolution in nematodes, these dramatic genetic differences suggest extensive, largely phenotypically "silent" changes in the genetic programmes orchestrating nematode development.

\section{Core developmental pathways differ between nematodes}

There are important differences in cell behaviour during early embryogenesis between $R$. culicivorax and C. elegans $[33,34]$. We used the genomic data to follow up on some of the striking contrasts between the dorylaim and the rhabditid patterns of development: establishment of primary axis polarity, segregation of maternal message within the early embryo, hypodermis formation, the vulval specification pathways, epigenetic pathways (especially DNA methylation), sex determination and light sensing (see Additional file 1).

The mechanisms of sex determination differ considerably among animals and it has been claimed to be one of the developmental programs most influenced by developmental system drift [16]. Divergence in sex determination pathways is thus not unexpected. While sex is determined by $\mathrm{X}$ to autosome ratio in C. elegans [66], sex ratios in $R$. culicivorax are likely to be environmentally determined through in-host nematode density [67]. Environmental sex determination is found in many nematode taxa, including Strongyloididae and Meloidogyninae (both Tylenchina), taxa more closely related to C. elegans. In C. elegans, the $\mathrm{X}$ to autosome ratio is read by the master switch XOL-1 [68], which acts through the three $s d c$ genes [69-71] to regulate the secretion of HER-1, a ligand for the TRA-2 receptor [72-74]. TRA-2 in turn

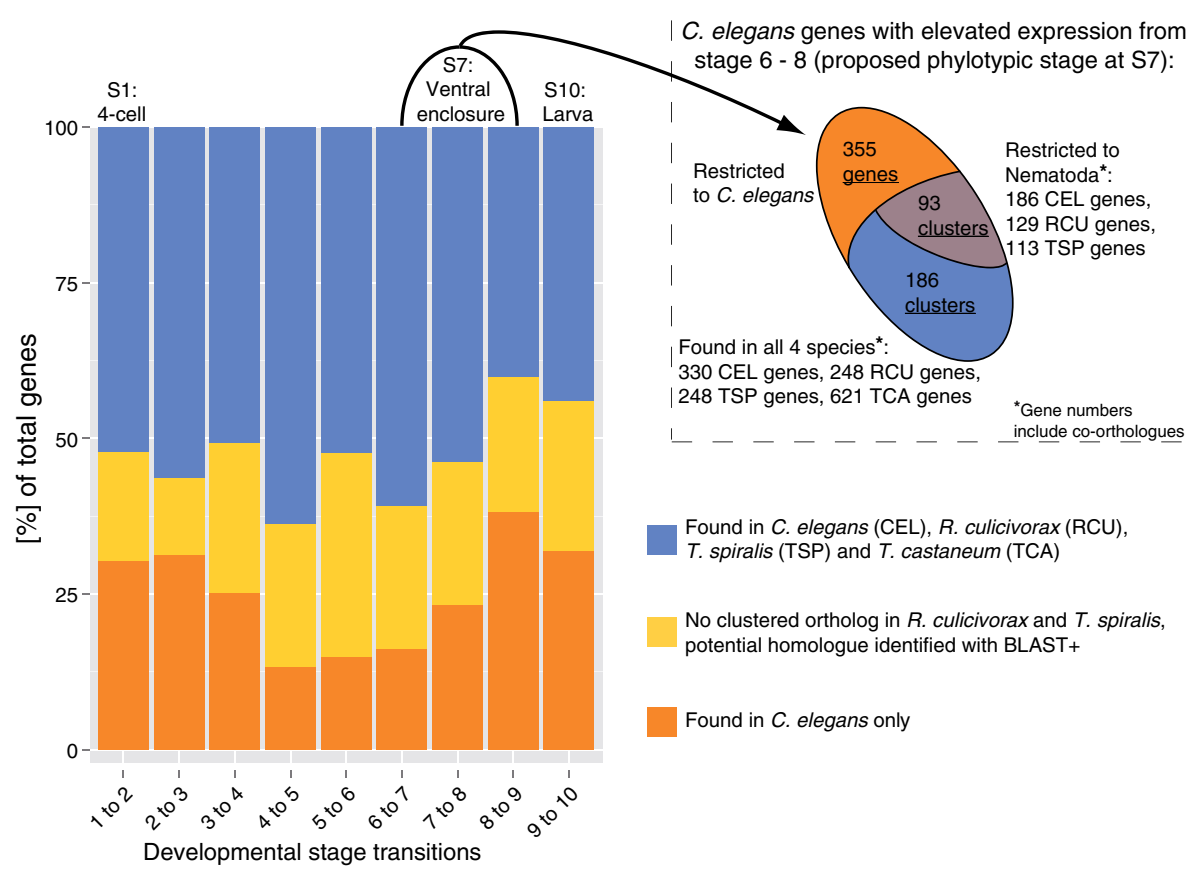

Figure 3 Many genes that are developmentally important in Caenorhabditis elegans were not present in Romanomermis culicivorax or Trichinella spiralis. R. culicivorax and T. spiralis orthologues of the 1,725 genes identified as important in embryogenesis in an analysis of gene expression in Caenorhabditis species [61] were sought. For each embryonic stage (1-10) in C. elegans we calculated the proportion of these genes that were apparently unique to the genus Caenorhabditis. The inset depicts numbers of two sets of genes and corresponding clusters that could play a role in a phylotypic stage of Nematoda or all Ecdysozoa, respectively. 
negatively regulates a complex of fem genes, which regulates nuclear translocation of TRA-1, the final shared step in the pathway that switches between male and hermaphrodite systems. No credible homologues of XOL1, SDC-1, SDC-2, SDC-3, HER-1 or TRA-2 in either T. spiralis or $R$. culicivorax were detected through OrthoMCL and re-confirmation with BLAST+ (Table 3; Additional file 2), and thus these species are unlikely to use the HER-1 - TRA-2 ligand-receptor system to coordinate sexual differentiation.

Other developmental processes are however more conserved between metazoan taxa. In C. elegans and many other animals par genes are essential for cell polarisation [75]. Polarised distribution of PAR proteins results in the restriction of mitotic spindle rotation to the germline cell in the C. elegans two-cell stage [76-78]. This rotation is not observed in $R$. culicivorax [33]. The division pattern of $C$. elegans mutants lacking par-2 and par-3 genes resembles that of the early $R$. culicivorax embryo $[33,79]$. The par2 gene was absent from both $R$. culicivorax and T. spiralis (Figure 4; Table 3). Additionally, no orthologues for the par-2-interacting genes let-99, gpr-1 or gpr-2, required for proper embryonic spindle orientation in C. elegans [80], were identified in the dorylaims using OrthoMCL clustering or sensitive BLAST + searches. Although we identified a protein with weak similarity to par-3 in $R$. culicivorax, this was so divergent from C. elegans, T. castaneum and $T$. spiralis par-3 that it was not clustered in our analysis. In D. melanogaster a par-3 orthologue, bazooka, functions in anterior-posterior axis formation [81], but par-2 is absent from the fly. Thus, we hypothesise that the PAR-3/PAR2 system for regulating spindle positioning evolved within the lineage leading to the genus Caenorhabditis. If the divergent par-3-like gene in $R$. culicivorax is involved in axis formation, it probably interacts with different partner proteins.

Once polarity has been established in the early C. elegans embryo, many maternal messages are differentially segregated into anterior or posterior blastomeres $[78,82]$. MEX-3 is an RNA-binding protein translated from maternally-provisioned mRNAs found predominantly in early anterior blastomeres [83,84]. We identified a highly divergent MEX-3 orthologue in $R$. culicivorax, but no orthologue in $T$. spiralis. We explored embryonic expression of mex-3 in R. culicivorax embryos using in situ hybridisation (Figure 5). In the fertilized egg the mex-3 mRNA is initially equally distributed. Prior to first cleavage it is segregated to the anterior pole and thus becomes essentially restricted to the somatic S1 blastomere (for nomenclature, see [14]). With the division of S1 it is localized to both daughter cells. After the 4-cell stage the signal disappears gradually. This expression pattern is similar to that of C. elegans mex-3, affirming that the $R$. culicivorax gene is likely to be an orthologue retaining
Table 3 Presence and absence of selected* C. elegans proteins in Dorylaimia

\begin{tabular}{ccc}
\hline Protein & T. spiralis & R. culicivorax \\
\hline CDC-42 & Early asymmetry & \\
PKC-3 & + & + \\
GPR-1 & + & + \\
GPR-2 & - & - \\
PAR-2 & - & - \\
PAR-6 & - & - \\
MES-6 & + & + \\
MES-3 & + & + \\
MES-4 & - & - \\
GFL-1 & - & - \\
LET-70 & + & +
\end{tabular}

\begin{tabular}{lcc}
\hline & Axis formation & + \\
\hline NUM-1 & + & - \\
ZIM-1 & - & - \\
MES-2 & - & - \\
POS-1 & - & + \\
SMA-6 & + & - \\
SET-2 & - & + \\
UBC-18 & + & - \\
LET-99 & - & - \\
OOC-3 & - & + \\
OOC-5 & + & + \\
GPA-16 & + & - \\
PAR-5 & - & - \\
ATX-2 & - & - \\
MEX-5 & - & - \\
MEX-6 & - & - \\
UNC-120 & - & - \\
NOS-2 & - & - \\
OMA-1 & - & + \\
RME-2 & + & - \\
SPN-4 & - & - \\
\hline & - & - \\
\hline
\end{tabular}

\begin{tabular}{lcc}
\hline & Sex determination & \\
\hline XOL-1 & - & - \\
HER-1 & - & - \\
SEX-1 & + & + \\
FOX-1 & + & + \\
SDC-1 & - & - \\
SDC-2 & - & - \\
SDC-3 & - & - \\
TRA-2 & - & - \\
FEM-1 & + & + \\
FEM-2 & + & +
\end{tabular}


Table 3 Presence and absence of selected* C. elegans proteins in Dorylaimia (Continued)

\begin{tabular}{lcc}
\hline Protein & T. spiralis & R. culicivorax \\
\hline AFF-1 & Hypodermis and vulva formation & \\
BAR-1 & - & - \\
CEH-2 & - & - \\
CEH-27 & - & - \\
GRL-15 & - & - \\
INX-5 & - & - \\
LIN-1 & - & - \\
PEB-1 & - & - \\
ELT-3 & - & - \\
ELT-1 & - & - \\
SMA-3 & + & + \\
SMA-5 & - & - \\
\hline
\end{tabular}

*For additional proteins see Additional files 2 and 4.

similar functions. However, despite the presence, and apparent conservation of the mex-3 expression pattern, we were unable to identify other interacting partners of the $C$. elegans MEX-3 protein, such as MEX-5, MEX-6 and SPN-4 in either dorylaim species. While MEX-5 and MEX-6 are important for controlled MEX-3 expression in C. elegans [85], the apparent absence of SPN-4 in $R$. culicivorax and T. spiralis is particularly intriguing. SPN-4 links embryonic polarity conferred by the par genes and partners to cell fate specification through maternally deposited mRNAs and proteins [86,87]. Our findings suggest that the core regulatory logic of the early control of axis formation and cell fate specification must differ significantly between the dorylaim species and C. elegans.

The hypodermis in C. elegans is derived from specific descendants of the anterior and posterior founder cells [88]. In contrast, in R. culicivorax hypodermis is derived from descendants of a single cell [34]. Several C. elegans genes expressed in the hypodermis or associated with hypodermal development were absent from $R$. culicivorax and T. spiralis (see Table 3 and Additional file 3). For example the GATA-like transcription factors ELT-1 and ELT-3 act redundantly in C. elegans [89]. ELT-3 was absent from the dorylaim species, but ELT-1 was conserved in $R$. culicivorax, T. spiralis and T. castaneum. Thus, ELT-3 appears to be an innovation in the rhabditid lineage, suggesting changes of interaction complexity during nematode evolution.

In C. elegans, vulva formation is highly dependent on initial inductive signals from the anchor cell that activate

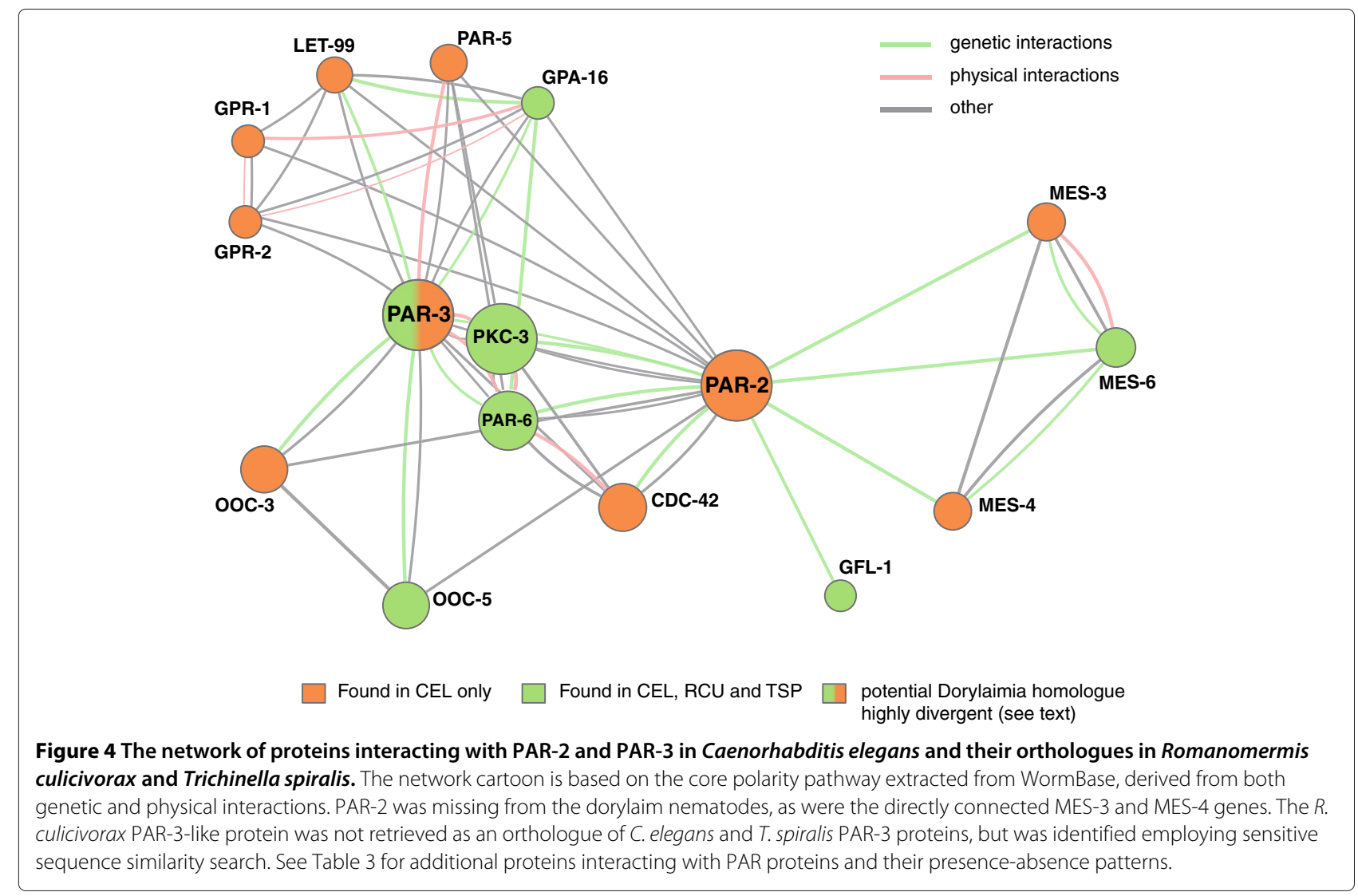



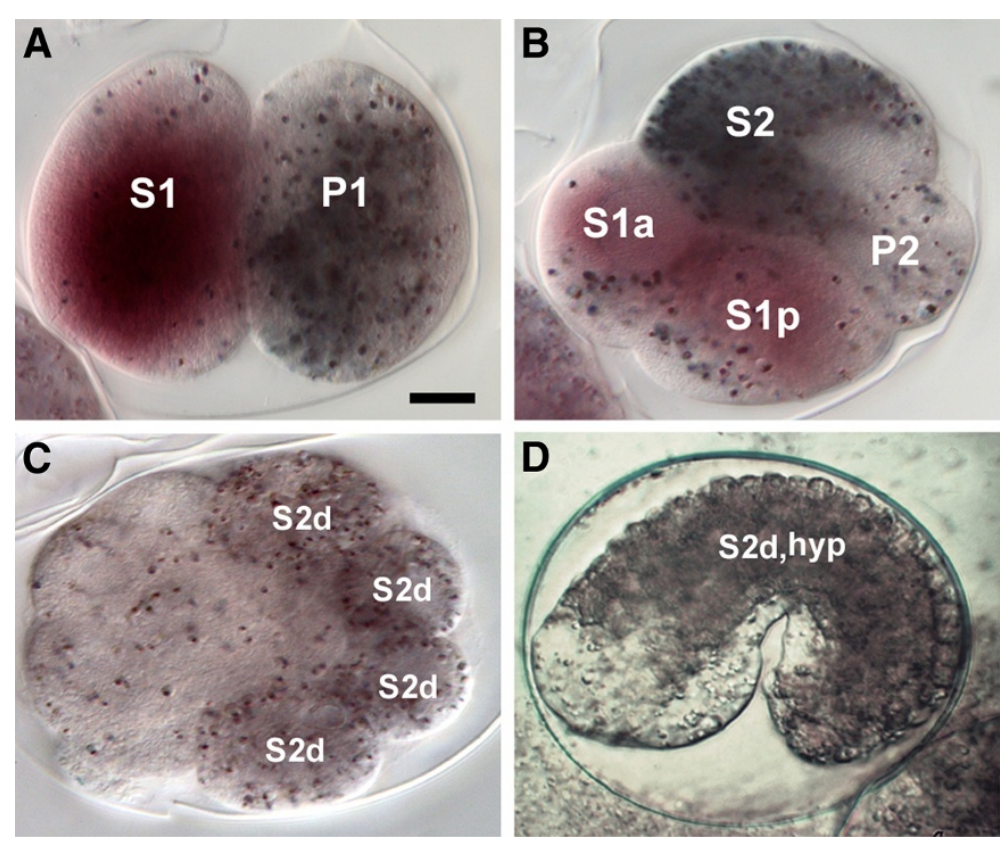

Figure 5 In situ hybridisation mapping of mex-3 mRNA distribution in early embryos of Romanomermis culicivorax. We used the R. culicivorax mex-3 gene to prove application of the in situ technique in this species and investigated the segregation patterns of segregation of this maternal RNA in early development. The $R$. culicivorax mex-3 expression pattern is similar to that of C. elegans [83]. R. culicivorax embryos contain dark pigment granules that are asymmetrically segregated in development. (A) At the 2-cell stage, maternal mex-3 mRNA is detected in the S1 blastomere. The cytoplasmic pigment granules are predominantly in the P1 blastomere. (B) At the 4-cell stage, mex-3 mRNA is detected in daughters of the anterior S1 cell. Cytoplasmic pigment granules are predominantly in the S2 blastomere. (C) At a later stage (>20 cells), mex-3 mRNA is absent. The pigment granules are found in descendants of S2 (S2d). (D) During early morphogenesis, the pigment granules are found in S2 descendants forming hypodermis, (S2d, hyp). (A-C) fixed embryos; (D) live embryo. Scale bar $10 \mu \mathrm{m}$. Orientation: anterior left.

a complex gene regulatory network, which drives tissue specific cell division and differentiation. The evolutionary plasticity of this system has been explored in rhabditid nematodes, revealing the changing relative importance of cell-cell interactions, inductions, and lineage-autonomous specifications [90,91]. The signal transduction pathways include a RTK/RAS/MAPK cascade, activated by EGFand wnt-signalling [92]. Among the downstream targets in C. elegans are for example LIN- 1 and the $\beta$-catenin BAR1 , which in turn regulates the HOX-5 orthologue LIN-39 [93-95]. These important regulators of vulva development are completely absent from the genomes of $R$. culicivorax and T. spiralis (Table 3 and Additional file 2). We identified a $R$. culicivorax protein with low similarity to C. elegans BAR-1 (24\% sequence identity). However, this protein is not clustered with other dorylaim proteins, and appears to be either a duplication of the $\beta$-catenin ortholog HMP- 2 or another armadillo repeatcontaining protein rather than an orthologue of BAR-1 (see Additional file 5). These shared patterns of absence again suggest that similar morphological structures can be generated with very different genetic underpinnings. Vulva formation in the dorylaims may be regulated without the BAR-1 - LIN-39 interaction, as observed in P. pacificus [96]. In C. elegans Hox gene expression is cell-lineage dependent $[97,98]$, organised so that the cells that express specific Hox genes are clustered along the anterior-posterior axis (see e.g. [99]). It will be informative to test whether in $R$. culicivorax and other non-rhabditid nematodes Hox genes act in an axis position-dependent, but cell lineage-independent manner, as observed in many other animals, notably arthropods [100,101]. Epigenetic regulation is key to developmental processes in many animals, but its roles in $C$. elegans are more muted (see above). Notably C. elegans is depleted for chromatin remodelling genes of the Polycomb and Trithorax groups [102]. It is intriguing that we found orthologues of T. castaneum pleiohomeotic in $R$. culicivorax and T. spiralis, and orthologs of T. castaneum trithorax and Sex comb on midleg $(\mathrm{Scm})$ in $R$. culicivorax. This suggests that dorylaim chromatin restructuring mechanisms may be more arthropod-like than in C. elegans. The presence of an intact methylation machinery and conserved chromatin re-modelling factors opens the prospects for a role for epigenetic modification in developmental regulation of dorylaim nematodes. 


\section{Defining a set of potential phylotypic stage genes}

While the examples above demonstrate considerable developmental system drift in Nematoda, we also identified many sets of orthologous proteins conserved between Dorylaimia and C. elegans. We asked if these could be correlated with functions in distinct developmental phases with a conserved phenotype. Shortly before the start of morphogenesis, at the point of ventral enclosure, nematode embryos from Chromadorea and Enoplea share a similar morphology [14]. Levin et al. [61] found that in five Caenorhabditis species a distinct set of genes had elevated expression around the ventral enclosure stage (their stage 7) (Figure 3) and proposed that this constitutes a "phylotypic stage" for nematodes. We used T. spiralis and R. culicivorax gene sets to refine and restrict this set of phylotypic stage genes. Of the 834 C. elegans genes with elevated expression between stages 6 to 8 [61], 355 had no orthologue in R. culicivorax, T. spiralis or T. castaneum. The remaining 479 phylotypic stage candidates from C. elegans were present in 279 of our OrthoMCL clusters. Of these clusters 93 were nematoderestricted containing $186 \mathrm{C}$. elegans proteins grouped with 129 R. culicivorax and 113 T. spiralis homologues. The remaining 186 clusters were part of the conserved ecdysozoan core proteome (see above) and contained 330 C. elegans proteins together with 248 R. culicivorax, 248 T. spiralis and 621 T. castaneum proteins (Figure 3; The total number of C. elegans candidates is larger than 479 due to the inclusion of co-orthologues in this species). In the set of phylotypic stage genes identified by Levin et al. [61] are proteins functioning in processes such as muscle and neuron formation, signalling between cells, and morphogenesis. This pattern was retained in the conserved clusters (see Additional file 5). Although time-resolved expression data will be needed to confirm the activity of these genes in developmental stages of $R$. culicivorax, their retention in the Dorylaimia supports their general importance. We can now sub-classify the set of conserved proteins expressed at the potential nematode phylotypic stage. A first, nematode-restricted set includes many proteins that are important for cuticle formation (e.g. collagen proteins) and some hedgehog-like proteins, expressed in the C. elegans hypodermis [103]. As cuticle formation follows ventral enclosure in nematodes, these proteins may be involved in this nematode-specific function. The second set, comprising clusters conserved between the nematodes and $T$. castaneum, contains many important developmental transcription factors, such as the Hox gene mab-5, other homeobox genes, and helix-loop-helix and $\mathrm{C} 2 \mathrm{H} 2$-type zinc finger transcription factors. This second set may represent a genetic backbone driving formation of phylotypic stage in diverse animal taxa, in accordance with the recent extension of the concept to Metazoa [104-106].

\section{Conclusions}

To be useful as a contrasting system to the canonical $C$. elegans model, any nematode species must be accessible to both descriptive and manipulative investigation. The reference genome for $R$. culicivorax lays bare the core machinery available for developmental regulation, and we have demonstrated that in situ hybridisation approaches are feasible for this species. Along with the long established, robust laboratory cultures, this makes $R$. culicivorax an attractive and tractable alternative model for understanding the evolutionary dynamics of nematode development. By combining the $R$. culicivorax genome with that of $T$. spiralis, we have been able to explore the molecular diversity of Dorylaimia, and provide robust contrasts with the intensively studied Rhabditida. Particularly surprising are the differences between $R$. culicivorax and T. spiralis. The R. culicivorax genome is much larger than that of T. spiralis, and contained a high proportion of repetitive sequence, including many transposable elements. Despite the phylogenetic and lifestyle affinities between the two dorylaims compared to C. elegans, the $R$. culicivorax genome retained many more genes in common with C. elegans than did T. spiralis. We suggest that T. spiralis may be an atypical representative of dorylaim nematodes, perhaps due to its highly derived life cycle.

Our analyses identified many genes apparently absent from the dorylaim genomes, despite relaxed analysis parameters. In particular, for genes identified as critical to C. elegans development but apparently absent from the dorylaims, we were unable to identify credible orthologues using sensitive search strategies. In this phylumspanning comparison, inferences of gene orthology can be obscured by levels of divergence. In addition, the gene family birth rate in the chromadorean lineage leading to C. elegans is high [25,27], and therefore C. elegans was expected to have many genes absent from the dorylaim species. Thus, we might not have found a R. culicivorax orthologue for a specific gene for three reasons: it may have arisen in the branch leading to C. elegans; its sequence divergence may be too great to permit clustering with potential homologs; or it was not assembled in the draft dorylaim genomes. The case of C. elegans PAR-3 and $D$. melanogaster bazooka illustrate some of these difficulties: the possible $R$. culicivorax orthologue was highly divergent. Whether or not we have been able to identify all the orthologues of the key C. elegans genes present in the $R$. culicivorax and T. spiralis genomes, the absence of an identified orthologue maximally implies loss from the genome, and minimally implies significant sequence divergence. In the latter case this would most likely cause changes in the networks and pathways in which genes interact to deliver biological function.

Between the model nematode C. elegans and arthropod models such as T. castaneum many key mechanisms 
governing early cell patterning are divergent [76]. Our data strongly support the view that major variation also exists within Nematoda. T. spiralis and $R$. culicivorax both lack orthologues of genes involved in core developmental processes in C. elegans, and many of these C. elegans genes appear to be restricted to the Rhabditida. It is thus doubtful that these processes are regulated by same molecular interactions across the phylum. We suggest that developmental system drift has played a major role in nematode evolution. The phenotypic conservatism associated with the vermiform morphology of nematodes [107] has fostered unjustified expectations concerning the conservation of genetic programmes that determine these morphologies. Despite this divergence in developmental systems, we were able to define two sets of conserved genes possibly active in a taxon-specific phase of ventral enclosure and cuticle formation in Nematoda, and in a potential phylotypic stage of Ecdysozoa. The advent of robust, affordable and rapid genome sequencing also opens the vista of large-scale comparative genomics of development across the phylum Nematoda [29] to better understand the diversity of the phylum and also place the remarkable $C$. elegans model in context of its peers. It will next be necessary to extend these studies to a broader sampling of developmental pathway genes from a wider and representative sampling of nematode genomes across the full diversity of the phylum. We have highlighted a few of the possible avenues a research programme could follow: early axis formation and polarisation, the specification of hypodermis, sex determination, vulva formation, the roles of epigenetic processes in developmental regulation and the confirmation of potential "phylotypic stage genes" with expression analysis in $R$. culicivorax.

\section{Methods}

\section{Sequencing and genome assembly}

Genomic DNA was extracted from several hundred, mixed-sex, adult $R$. culicivorax specimens from a culture first established in Ed Platzer's laboratory in Riverside, California. Illumina paired end and mate pair sequencing with libraries of varying insert sizes, and Roche 454 single end sequencing, was performed at the Cologne Center for Genomics (CCG: http://www.ccg.uni-koeln.de). A Roche 454 dataset of transcriptome reads from cDNA synthesised from mixed developmental stages and sexes was also generated (see Additional file 1: Table S1 for details of data generated).

The quality of the raw data was assessed with FastQC (v.0.9; http://www.bioinformatics.babraham.ac. $\mathrm{uk} /$ projects/fastqc/). Adapter sequences and low quality data were trimmed from the Illumina paired end data with custom scripts (see http://github.com/sujaikumar/ assemblage) and from the mate pair libraries with Cutadapt (v.1.0) [108]. We constructed a preliminary genome assembly, with relaxed insert size parameters, from the paired end Illumina libraries with the de-novoassemble option of the clcAssemblyCell (v.4.03b) [109]. We validated the actual insert sizes of our libraries by mapping back the reads to this preliminary assembly using clcAssemblyCell. The preliminary assembly was also used to screen out bacterial and other contaminant data [110]. The transcriptome data were assembled with Roche GSAssembler (Newbler; version 2.5). For the production assembly, we explored assembly parameters using different mixes of our data, evaluating each for total span, maximal contig lengths, N50, number of contigs, representation of the transcriptome, and conserved eukaryotic gene content (using the CEGMA pipeline v.2.1 [36]). The most promising assembly was scaffolded with the filtered Illumina mate pair read sets using SSPACE (v.1.2) [111]. As our genomic DNA derived from a population of nematodes of unknown genetic diversity, we removed short contigs that mapped entirely within larger ones using Cd-hit (v.4.5.7) [38] at a 95\% cutoff. A final round of superscaffolding was performed, linking scaffolds that had logically consistent matches to the transcriptome data based on BLAT [35] hits and processed with SCUBAT (B. Elsworth, pers. comm.; http://github. com/elswob/SCUBAT). The final genome assembly was again assessed for completeness by assessing the mapping of the transcriptome contigs and with the CEGMA pipeline [36].

\section{Genome annotation}

RepeatMasker (v.3.3.0) [112,113], RepeatFinder [114] and RepeatModeler (v.1.0.5; http://www.repeatmasker. org/RepeatModeler.html; combining RECON (v.1.07) [115] and RepeatScout (v.1.05) [116]), were used to identify known and novel repetitive elements in the $R$. culicivorax genome. We employed the MAKER pipeline[37] to find genes in the $R$. culicivorax genome assembly. In a first pass, the SNAP gene predictor included in MAKER was trained with a CEGMA [36] derived output of predicted highly conserved genes. As additional evidence we included the transcriptome assembly and a set of approximately 15,000 conserved nematode proteins derived from the NEMBASE4 database[117] (recalculated by J. Parkinson; pers. comm.). In the second, definitive, pass we used the gene set derived from this first MAKER iteration to train AUGUSTUS [39] inside the MAKER pipeline for a second run, also including evidence from transcriptome to genome mapping obtained with GenomeThreader [118]. Codon usage in R. culicivorax, T. spiralis, and C. elegans was calculated using INCA (v2.1) [119]. Results were then compared to data from [120] (see Additional files 1 and 6).

We used Blast2GO (Blast2GO4Pipe, v.2.5, January 2012 database issue) [121] to annotate the gene set with Gene 
Ontology terms [122], based on BLAST matches with expect values less than $1 \mathrm{e}^{-5}$ to the UniProt/SwissProt database (March 2012 snapshot), and domain annotations derived from the InterPro database [123]. Comparison of annotations between three nematode species ( $R$. culicivorax, C. elegans, and T. spiralis) and, as a reference outgroup, the holometabolous coleopteran arthropod Tribolium castaneum, was based on GO Slim data retrieved with Blast2GO. RNA genes were predicted using INFERNAL (v.1.0.2)[41] and the Rfam database [124], and tRNAscan-SE (v.1.3.1) [42].

\section{Orthology screen}

We inferred clusters of orthologous proteins between R. culicivorax, T. spiralis, and C. elegans, and the beetle T. castaneum using OrthoMCL (v.2.0.3) [125]. T. spiralis, C. elegans and T. castaneum protein sets were downloaded from NCBI and WormBase (see Additional file 1: Table S3) and redundancy screened with Cd-hit at the $99 \%$ threshold. We selected an inflation parameter of 1.5 for MCL clustering (based on [126,127]) within OrthoMCL to generate an inclusive clusterings in our analysis likely to contain even highly diverged representatives from the four species. In analyses of selected developmental genes, clusters were manually validated using NCBI-BLAST+ [53]. We affirmed the uniqueness of $C$. elegans proteins identified as lacking homologues in the enoplean nematodes by comparing them to the $R$. culicivorax proteome using BLAST. Those with no significant matches at all (all matches with E-values $>1 \mathrm{e}^{-5}$ ) were classified as confirmed absent. Those having matches with E-values $<1 \mathrm{e}^{-5}$ were investigated further by surveying the cluster memberships of the R. culicivorax matches. If the $R$. culicivorax protein was found to cluster with a different $C$. elegans protein, the uniqueness to $C$. elegans was again confirmed. If the $R$. culicivorax protein did not cluster with an alternative $C$. elegans protein, we reviewed the BLAST statistics (E-value, identity and sequence coverage) of the match and searched the GenBank non redundant protein database for additional evidence of possible orthology. Only if these tests yielded no indication of direct orthology was the $C$. elegans protein designated absent from the enoplean set. Further details of the process are given in Additional file 5.

We identified the protein sequences of 1,725 genes differentially expressed in C. elegans developmental stages [61] and selected, using our OrthoMCL clustering, those apparently lacking orthologues in R. culicivorax and $T$. spiralis (verified as above). Using Wormbase (http:// www.wormbase.org, release WS233) we surveyed the $C$. elegans-restricted genes for their experimentally-defined roles in development.

Custom Perl scripts were used to group orthoMCL clusters on the basis of species membership patterns. The sets of clusters that contained (i) both T. spiralis and $R$. culicivorax members but no C. elegans members and (ii) $T$. spiralis and $R$. culicivorax and T. castaneum members but no C. elegans members were surveyed for GO annotations enriched in comparison to the whole C. elegans proteome (sets $\mathrm{i}$ and ii) and the T. castaneum proteome (set i), conducting Fisher's exact test as implemented in Blast2GO. Due to the small size of both sets compared to the large reference set, $\mathrm{p}$-values could not be corrected for multiple testing. To improve annotation reliability, these proteins were recompared (using BLAST) to the UniProt/SwissProt database and run through the Blast2GO pipeline as described above.

\section{Whole-mount in situ hybridization}

For in situ hybridisation we modified the freeze-crack procedure described previously for C. elegans [128] and revised by Maduro et al. (2007; http://www.faculty.ucr. $\mathrm{edu} / \sim$ mmaduro/resources.htm). In particular, to achieve reliable penetration of the durable $R$. culicivorax egg envelopes we initially partly removed the protective layer by incubation in alkaline bleach solution (see [33]). Digoxygenine-labeled sense and antisense RNA probes were generated from linearized $\mathrm{pBs}$ vectors (Stratagene, La Jolla, USA) containing a $400 \mathrm{bp}$ fragment of $R$. culicivorax mex-3 via run off in vitro transcription with $\mathrm{T} 7$ or $\mathrm{T} 3$ RNA-polymerase according to the manufacturer's protocol (Roche, Mannheim, Germany). The concentration of the labelled probes was about $300 n g \times m l^{-1}$.

\section{Additional files}

Additional file 1: Supplementary data figures and tables.

Additional file 2: Analysis of OrthoMCL output by BLAST+. BLAST+ results for specific C. elegans proteins not found in a cluster with Dorylaimia proteins.

Additional file 3: Fisher's exact test data. $\mathrm{GO}$ terms enriched in a set of protein clusters shared between Dorylaimia in comparison to (i) C. elegans and (ii) T. castaneum proteomes.

Additional file 4: Levin data. Genes identified as being differentially expressed in Caenorhabditis development by Levin et al. [61].

Additional file 5: Analysis of Phylotypic stage genes. C. elegans orthologues of genes possibly acting in (i) a potential nematode specific phylotypic stage and (ii) a metazoan phylotypic stage.

Additional file 6: Codon usage in R. culicivorax. Codon usage data.

Competing interests

The authors declare that they have no competing interests.

\section{Authors' contributions}

PHS conceived study, assembled and annotated the genome, conducted analyses and wrote paper; MK conceived study, conducted analyses and wrote part of the paper; CK conceived part of the study, conducted analyses on developmental expression set and wrote part of the paper; GDK helped with genome assembly and annotation; SK helped with genome assembly and wrote/provided Perl scripts; JRC analysed MEX-3 dataset; NAN analysed PAR dataset; DS analysed SEX determination dataset; KM conducted RNA sequencing and initial EST assembly; PH performed preparative laboratory 
experiments and conceived sequencing strategy; JA conceived sequencing strategy and conducted genome sequencing; PF helped with initial genome pre-assembly; PN initiated study and conceived sequencing strategy; WKT conceived parts of study; MLB conceived study and wrote paper; ES initiated and conceived study and wrote paper. All authors read and approved the final manuscript.

\section{Acknowledgements}

We are indebted to E. Platzer, Riverside, for the continuous supply with R culcivorax nematodes. We thank J. Schulze, Cologne, for advice on nematode cultivation and C. Becker and K. Konrad for expert technical assistance in the genome sequencing experiments. We are also grateful to H. Oezden, Cologne for assistance with In-situ hybridisations. We thank J. Parkinson, Toronto, for providing a conserved NEMBASE4 protein set, Elizabeth Martínez Salazar, Zacatecas, Mexico, for Feulgen C-value data and A. H. Jay Burr, Vancouver, Canada for sharing preliminary results on phototaxis in $R$. culicivorax. Assemblies and other computations were conducted on the HPC cluster "CHEOPS" at the University of Cologne (http://rrzk.uni-koeln.de/cheops.html).

\section{Funding}

This work was partly funded through the SFB 680: "Molecular Basis of Evolutionary Innovations". Philipp H. Schiffer is funded by the VolkswagenStiftung in the "Förderinitiative Evolutionsbiologie". Gerogios D. Koutsovoulos is funded by a UK BBSRC Research Studentship and an Overseas Reasearch Studentship from the University of Edinburgh. Additional Funding came through the BMBF-Projekt "NGSgoesHPC".

\section{Accession numbers}

Raw genome and transcriptome sequence data reported in this manuscript have been deposited in the ERA under accession ERP002111 (http://www.ebi. ac.uk/ena/data/view/ERP002111), and assembled genomic contigs deposited in the ENA INSDC database under accession numbers

CAQS01000001-CAQS01062537. Annotation information and additional data are available through (http://romanomermis.nematod.es).

\section{Author details}

'Zoologisches Institut, Universität zu Köln, Cologne, NRW, Germany, ORCiD:0000-0001-6776-0934. ${ }^{2}$ Institute of Evolutionary Biology, School of Biological Sciences, The University of Edinburgh, Edinburgh, Scotland, UK. ${ }^{3}$ Institute für Entwicklungsbiologie, Universität zu Köln, Cologne, NRW, Germany. ${ }^{4}$ Hubbard Center for Genome Studies, University of New Hampshire, Durham, NH, USA. ${ }^{5}$ Cologne Center for Genomics, Universität zu Köln, Cologne, NRW, Germany.

Received: 7 May 2013 Accepted: 17 December 2013 Published: 27 December 2013

\section{References}

1. Maduro MF: Cell fate specification in the C. elegans embryo. Dev Dyn 2010, 239:1315-1329.

2. Sulston JE, Schierenberg E, White JG, Thomson JN: The embryonic cell lineage of the nematode Caenorhabditis elegans. Dev Biol 1983, 100:64-119

3. Blaxter M, de Ley P, Garey J, Liu L, Scheldeman P, Vierstraete A, Vanfleteren J, Mackey L, Dorris M, Frisse L: A molecular evolutionary framework for the phylum Nematoda. Nature 1998, 392(6671):71-75.

4. Meldal B, Debenham N, de Ley P, de Ley I, Vanfleteren J, Vierstraete A, Bert W, Borgonie G, Moens T, Tyler P, Austen M, Blaxter M, Rodgers A, Lambshead P: An improved molecular phylogeny of the Nematoda with special emphasis on marine taxa. Mol Phylogenet Evol 2007, 42(3):622-636.

5. Boveri T: Die Entwicklung von Ascaris megalocephala mit besonderer Ruecksicht auf die Kernverhaeltnisse. Fischer: Festschrift fuer Carl von Kupffer; Jena; 1899.

6. Müller $\mathrm{H}$ : Beitrag zur Embryonalentwicklung von Ascaris megalocephala. Zoologica 1903, 41:60.

7. Vangestel S, Houthoofd W, Bert W, Borgonie G: The early embryonic development of the satellite organism Pristionchus pacificus: differences and similarities with Caenorhabditis elegans. Nematology 2008, 10:301-312.

8. Skiba F, Schierenberg E: Cell lineages, developmental timing, and spatial pattern formation in embryos of free-living soil nematodes. Dev Biol 1992, 151(2):597-610.
9. Lahl V, Schulze J, Schierenberg E: Differences in embryonic pattern formation between Caenorhabditis elegans and its close parthenogenetic relative Diploscapter coronatus. Int J Dev Biol 2009, 53(4):507-515.

10. Brauchle M, Kiontke K, Macmenamin P, Fitch DHA, Piano F: Evolution of early embryogenesis in rhabditid nematodes. Dev Biol 2009, 335:253-262.

11. Wiegner O, Schierenberg E: Specification of gut cell fate differs significantly between the Nematodes Acrobeloides nanus and Caenorhabditis elegans. Dev Biol 1998, 204:3-14.

12. Wiegner O, Schierenberg E: Regulative development in a nematode embryo: a hierarchy of cell fate transformations. Dev Biol 1999, 215:1-12.

13. Voronov DA, Panchin YV: Cell lineage in marine nematode Enoplus brevis. Dev 1998, 125:143-150

14. Schulze J, Schierenberg E: Evolution of embryonic development in nematodes. EvoDevo 2011, 2:18.

15. Schulze J, Houthoofd W, Uenk J, Vangestel S, Schierenberg E: Plectus - a stepping stone in embryonic cell lineage evolution of nematodes. EvoDevo 2012, 3:13.

16. True JR, Haag ES: Developmental system drift and flexibility in evolutionary trajectories. Evol Dev 2001, 3(2):109-119.

17. Celegans Sequencing Consortium: Genome sequence of the nematode C. elegans: a platform for investigating biology. Science 1998, 282(5396):2012-2018.

18. Stein LD, Bao Z, Blasiar D, Blumenthal T, Brent MR, Chen N, Chinwalla A, Clarke L, Clee C, Coghlan A, Coulson A, D'eustachio P, Fitch DHA, Fulton LA, Fulton RE, Griffiths-Jones S, Harris TW, Hillier LW, Kamath R, Kuwabara PE, Mardis ER, Marra MA, Miner TL, Minx P, Mullikin JC, Plumb RW, Rogers J, Schein JE, Sohrmann M, Spieth J, et al.: The genome sequence of, Caenorhabditis briggsae: a platform for comparative genomics. PLoS Biol 2003, 1(2):E45.

19. Mortazavi A, Schwarz EM, Williams B, Schaeffer L, Antoshechkin I, Wold BJ, Sternberg PW: Scaffolding a Caenorhabditis nematode genome with RNA-seq. Genome Res 2010, 20(12):1740-1747.

20. Dieterich C, Clifton SW, Schuster LN, Chinwalla A, Delehaunty K, Dinkelacker I, Fulton L, Fulton R, Godfrey J, Minx P, Mitreva M, Roeseler W, Tian H, Witte H, Yang SP, Wilson RK, Sommer RJ: The Pristionchus pacificus genome provides a unique perspective on nematode lifestyle and parasitism. Nature Genet 2008, 40(10):1193-1198.

21. Jex AR, Liu S, Li B, Young ND, Hall RS, Li Y, Yang L, Zeng N, Xu X, Xiong Z, Chen F, Wu X, Zhang G, Fang X, Kang Y, Anderson GA, Harris TW, Campbell BE, Vlaminck J, Wang T, Cantacessi C, Schwarz EM, Ranganathan S, Geldhof P, Nejsum P, Sternberg PW, Yang H, Wang J, Wang J, Gasser RB: Ascaris suum draft genome. Nature 2011, 479(7374):529-533.

22. Ghedin E, Wang S, Spiro D, Caler E, Zhao Q, Crabtree J, Allen JE, Delcher AL, Guiliano DB, Miranda-Saavedra D, Angiuoli SV, Creasy T, Amedeo P, Haas B, El-Sayed NM, Wortman JR, Feldblyum T, Tallon L, Schatz M Shumway M, Koo H, Salzberg SL, Schobel S, Pertea M, Pop M, White O, Barton GJ, Carlow CKS, Crawford MJ, Daub J, et al.: Draft genome of the filarial nematode parasite Brugia malayi. Science 2007, 317(5845):1756-1760.

23. Godel C, Kumar S, Koutsovoulos G, Ludin P, Nilsson D, Comandatore F, Wrobel N, Thompson M, Schmid CD, Goto S, Bringaud F, Wolstenholme A, Bandi C, Epe C, Kaminsky R, Blaxter M, Mäser P: The genome of the heartworm, Dirofilaria immitis, reveals drug and vaccine targets. FASEB J 2012, 26(11):4650-4661.

24. Abad P, Gouzy J, Aury JM, Castagnone-Sereno P, Danchin EGJ, Deleury E, Perfus-Barbeoch L, Anthouard V, Artiguenave F, Blok VC, Caillaud MC, Coutinho PM, Dasilva C, De Luca F, Deau F, Esquibet M, Flutre T, Goldstone JV, Hamamouch N, Hewezi T, Jaillon O, Jubin C, Leonetti P, Magliano M, Maier TR, Markov GV, Mcveigh P, Pesole G, Poulain J, Robinson-Rechavi M, et al.: Genome sequence of the metazoan plant-parasitic nematode, Meloidogyne incognita. Nature Biotechnol 2008, 26(8):909-915.

25. Kikuchi T, Cotton JA, Dalzell JJ, Hasegawa K, Kanzaki N, Mcveigh P, Takanashi T, Tsai IJ, Assefa SA, Cock PJA, Otto TD, Hunt M, Reid AJ, Sanchez-Flores A, Tsuchihara K, Yokoi T, Larsson MC, Miwa J, Maule AG, Sahashi N, Jones JT, Berriman M: Genomic insights into the origin of 
parasitism in the emerging plant pathogen Bursaphelenchus xylophilus. PLoS Pathogens 2011, 7(9):e1002219.

26. Srinivasan J, Dillman AR, Macchietto MG, Heikkinen L, Lakso M, Fracchia KM, Antoshechkin I, Mortazavi A, Wong G, Sternberg PW: The draft genome and transcriptome of Panagrellus redivivus are shaped by the harsh demands of a free-living lifestyle. Genetics 2013, 193(4):1279-1295

27. Mitreva M, Jasmer DP, Zarlenga DS, Wang Z, Abubucker S, Martin J, Taylor CM, Yin Y, Fulton LA, Minx P, Yang SP, Warren WC, Fulton RS, Bhonagiri $V$, Zhang X, Hallsworth-Pepin K, Clifton SW, Mccarter JP, Appleton J, Mardis ER, Wilson RK: The draft genome of the parasitic nematode Trichinella spiralis. Nature Genet 2011, 43(3):228-235.

28. Hope IA: Embryology, Developmental Biology and the Genome. In The Biology of Nematodes. 1st edition. Edited by Lee DL. New York: Tayler \& Francis; 2002:121-145.

29. Kumar S, Schiffer PH, Blaxter M: 959 Nematode Genomes: a semantic wiki for coordinating sequencing projects. Nucl Acids Res 2012, 40(D1):D1295-D1300.

30. Kumar S, Koutsovoulos G, Kaur G, Blaxter M: Toward 959 nematode genomes. Worm 2012, 1:0-8

31. Petersen JJ: Nematodes as biological control agents: Part I. Mermithidae. In Advances in Parasitology. Edited by Baker JR, Muller R. London: Academic Press; 1985:307-346.

32. Petersen JJ, Chapman HC, Willis OR, Fukuda T: Release of Romanomermis culicivorax for the control of Anopheles albimanus in El Salvador II. Application of the nematode. Ame J Trop Med Hyg 1978, 27(6):1268-1273.

33. Schulze J, Schierenberg E: Cellular pattern formation, establishment of polarity and segregation of colored cytoplasm in embryos of the nematode Romanomermis culicivorax. Dev Biol 2008, 315(2):426-436.

34. Schulze J, Schierenberg E: Embryogenesis of Romanomermis culicivorax: an alternative way to construct a nematode. Dev Biol 2009, 334:10-21.

35. Kent W: BLAT—the BLAST-like alignment tool. Genome Res 2002, 12(4):656.

36. Parra G, Bradnam K, Korf I: CEGMA: a pipeline to accurately annotate core genes in eukaryotic genomes. Bioinformatics 2007, 23(9):1061-1067.

37. Cantarel BL, Korf I, Robb SMC, Parra G, Ross E, Moore B, Holt C, Sánchez Alvarado A, Yandell M: MAKER: an easy-to-use annotation pipeline designed for emerging model organism genomes. Genome Res 2008, 18:188-196.

38. Li W, Godzik A: Cd-hit: a fast program for clustering and comparing large sets of protein or nucleotide sequences. Bioinformatics 2006 , 22(13):1658-1659.

39. Stanke $M$, Waack S: Gene prediction with a hidden Markov model and a new intron submodel. Bioinformatics 2003, 19(2):ii215-ii225.

40. Wang J, Mitreva M, Berriman M, Thorne A, Magrini V, Koutsovoulos G, Kumar S, Blaxter ML, Davis RE: Silencing of germline-expressed genes by DNA elimination in somatic cells. Dev Cell 2012, 23(5):1072-1080.

41. Nawrocki EP, Kolbe DL, Eddy SR: Infernal 1.0: inference of RNA alignments. Bioinformatics 2009, 25(10):1335-1337.

42. Lowe TM, Eddy SR: tRNAscan-SE: a program for improved detection of transfer RNA genes in genomic sequence. Nucl Acids Res 1997, 25(5):0955-0964.

43. Kumar S: Data for PhD thesis on next generation nematode genomes. 2012. http://dx.doi.org/10.6084/m9.figshare.96089.

44. Richards S, The T castaneum Genome Consortium: The genome of the model beetle and pest Tribolium castaneum. Nature 2008, 452(7190):949-955.

45. Schröder R, Beermann A, Wittkopp N, Lutz R: From development to biodiversity-Tribolium castaneum, an insect model organism for short germband development. Dev Genes Evol 2008, 218(3-4):119-126.

46. Chen F, Mackey AJ, Vermunt JK, Roos DS: Assessing performance of orthology detection strategies applied to eukaryotic genomes. PLOS ONE 2007, 2(4):e383.

47. Altschul S, Madden T, Schäffer A: Gapped BLAST and PSI-BLAST: a new generation of protein database search programs. Nucl Acids... 1997. [http://nar.oxfordjournals.org/content/25/17/3389.short]

48. Jensen RA: Orthologs and paralogs - we need to get it right. Genome Biol 2001, 2(8):interactions1002.1-1002.3.
49. Koonin E: Orthologs, paralogs, and evolutionary genomics. Ann Rev Genet 2005, 39:309-338.

50. Moreno-Hagelsieb G, Latimer K: Choosing BLAST options for better detection of orthologs as reciprocal best hits. Bioinformatics 2008, 24(3):319-324

51. Shaye DS, Greenwald I: OrthoList: A compendium of C. elegans Genes with human Orthologs. PLOS ONE 2011, 6(5):e20085.

52. Tautz D, Domazet-Lošo T: The evolutionary origin of orphan genes. Nat Rev Genet 2011, 12(10):692-702.

53. Altschul SF, Gish W, Miller W, Myers EW: Basic local alignment search tool. J Mol Biol 1990, 215:403-410.

54. Keeling PJ, Corradi N, Morrison HG, Haag KL, Ebert D, Weiss LM, Akiyosh $D E$, Tzipori S: The reduced genome of the parasitic microsporidian enterocytozoon bieneusi lacks genes for core carbon metabolism. Genome Biol Evol 2010, 2(0):304-309.

55. Bird A: DNA methylation patterns and epigenetic memory. Genes \& Dev 2002, 16:6-21

56. Gao F, Liu X, Wu XP, Wang XL, Gong D, Lu H, Xia Y, Song Y, Wang J, Du J, Liu S, Han X, Tang Y, Yang H, Jin Q, Zhang X, Liu M: Differential DNA methylation in discrete developmental stages of the parasitic nematode Trichinella spiralis. Genome Biol 2012, 13(10):R100.

57. Tran RK, Zilberman D, de Bustos C, Ditt RF, Henikoff JG, Lindroth AM, Delrow J, Boyle T, Kwong S, Bryson TD, Jacobsen SE, Henikoff S: Chromatin and siRNA pathways cooperate to maintain DNA methylation of small transposable elements in Arabidopsis. Genome Biol 2005, 6(11):R90.

58. Martienssen RA, Colot V: DNA methylation and epigenetic inheritance in plants and filamentous fungi. Science 2001 293(5532):1070-1074.

59. Eisenmann DM: Wnt signaling. WormBook 2005. [http://www. wormbook.org/chapters/www wntsignaling/wntsignaling.html]

60. Graham LD, Kotze AC, Fernley RT, Hill RJ: Molecular \& biochemical parasitology. Mol Biochem Parasito/ 2010, 171(2):104-107. [http://dx. doi.org/10.1016/j.molbiopara.2010.03.003]

61. Levin M, Hashimshony T, Wagner F, Yanai I: Developmental milestones punctuate gene expression in the caenorhabditis embryo. Dev Cell 2012, 22(5):1101-1108.

62. Phelan P: Innexins: members of an evolutionarily conserved family of gap-junction proteins. Biochimica et Biophysica Acta (BBA) Biomembranes 2005, 1711(2):225-245.

63. Jones AK, Sattelle DB: Functional genomics of the nicotinic acetylcholine receptor gene family of the nematode, Caenorhabditis elegans. BioEssays 2003, 26:39-49.

64. Antebi A: Nuclear hormone receptors in C. elegans. In Wormbook Edited by The C. elegans Research Community. WormBook; 2006. http:// www.wormbook.org.

65. Altun ZF, Chen B, Wang ZW, Hall DH: High resolution map of Caenorhabditis elegansgap junction proteins. Dev Dyn 2009, 238(8):1936-1950.

66. Haag $\mathrm{E}:$ The evolution of nematode sex determination: $C$. elegans as a reference point for comparative biology. In WormBook. Edited by The C. elegans Research Community: WormBook; 2005. http://www. wormbook.org.

67. Tingley GA, Anderson RM: Environmental sex determination and density-dependent population regulation in the entomogenous nematode Romanomermis culicivorax. Parasitol 1986, 92:431-449

68. Powell JR, Jow MM, Meyer BJ: The T-box transcription factor SEA-1 is an autosomal element of the $X: A$ signal that determines $C$. elegans sex. Dev Cell 2005, 9(3):339-349.

69. Chu DS, Dawes HE, Lieb JD, Chan RC, Kuo AF, Meyer BJ: A molecular link between gene-specific and chromosome-wide transcriptional repression. Genes \& Dev 2002, 16(7):796-805

70. Meyer B: X-Chromosome dosage compensation. In WormBook. Edited by The C. elegans Research Community. WormBook; 2005. http://www. wormbook.org.

71. Zarkower D: Somatic sex determination. In WormBook. Edited by The C. elegans Research Community. WormBook; 2006. http://www. wormbook.org.

72. Kuwabara PE, Okkema PG, Kimble J: tra-2 encodes a membrane protein and may mediate cell communication in the 
Caenorhabditis elegans sex determination pathway. Mol Biol Cell 1992, 3(4):461-473.

73. Goodwin EB, Ellis RE: Turning clustering loops: sex determination in Caenorhabditis elegans. Curr Biol 2002, 12(3):R111-R120.

74. Baldi C, Cho S, Ellis RE: Mutations in two independent pathways are sufficient to create hermaphroditic nematodes. Science 2009, 326(5955):1002-1005.

75. Goldstein B, Macara IG: The PAR proteins: fundamental players in animal cell polarization. Dev Cell 2007, 13(5):609-622.

76. Bowerman B: Embryonic polarity: Protein stability in asymmetric cell division. Curr Biol 2000, 10(17):R637-R641.

77. Severson AF, Bowerman B. J Cell Biol 2003, 161:21-26.

78. Gönczy P, Rose LS: Asymmetric cell division and axis formation in the embryo. In WormBook. Edited by The C. elegans Research Community. WormBook:2005. http://www.wormbook.org.

79. Cheng NN, Kirby CM, Kemphues KJ: Control of cleavage spindle orientation in Caenorhabditis elegans: the role of the genes par-2 and par-3. Genetics 1995, 139(2):549-559.

80. Wu JC, Rose LS: PAR-3 and PAR-1 inhibit LET-99 localization to generate a cortical band important for spindle positioning in Caenorhabditis elegans embryos. Mol Biol Cell 2007,

18(11):4470-4482.

81. Doerflinger H, Vogt N, Torres IL, Mirouse V, Koch I, Nusslein-Volhard C, St Johnston D: Bazooka is required for polarisation of the Drosophila anterior-posterior axis. Development 2010, 137(10):1765-1773.

82. Goldstein B, Frisse L, Thomas W: Embryonic axis specification in nematodes: evolution of the first step in development. Curr Biol 1998, 8(3):157-160.

83. Draper BW, Mello CC, Bowerman B, Hardin J, Priess JR: MEX-3 is a KH domain protein that regulates blastomere identity in early $C$. elegans embryos. Cell 1996, 87(2):205-216.

84. Huang N, Mootz D, Walhout A, Vidal M, Hunter CP: MEX-3 interacting proteins link cell polarity to asymmetric gene expression in Caenorhabditis elegans. Development 2002, 129(3):747-759.

85. Evans TC, Hunter CP: Translational control of maternal RNAs. In WormBook. Edited by The C. elegans Research Community. WormBook:2005. http://www.wormbook.org.

86. Gomes JE, Encalada SE, Swan KA, Shelton CA, Carter JC, Bowerman B: The maternal gene spn- 4 encodes a predicted RRM protein required for mitotic spindle orientation and cell fate patterning in early C. elegans embryos. Dev 2001, 128(21):4301-4314.

87. Labbé JC, Goldstein B: Embryonic development: A New SPN on cell fate specification. Curr Biol 2002, 12(11):R396-R398.

88. Simske JS, Hardin J: Getting into shape: epidermal morphogenesis in Caenorhabditis elegans embryos. BioEssays 2001, 23:12-23.

89. Gilleard JS, McGhee JD: Activation of hypodermal differentiation in the Caenorhabditis elegans embryo by GATA transcription factors ELT-1 and ELT-3. Mol Cell Bio/ 2001, 21(7):2533-2544.

90. Sommer R: As good as they get: cells in nematode vulva development and evolution. Curr Opin Cell Biol 2001, 13(6):715-720.

91. Kiontke K, Barriere A, Kolotuev I, Podbilewicz B, Sommer R, Fitch DHA Félix MA: Trends, stasis, and drift in the evolution of nematode vulva development. Curr Biol: CB 2007, 17(22):1925-1937.

92. Sternberg PW: Vulval development. In WormBook. Edited by The C. elegans Research Community. WormBook; 2005. http://www. wormbook.org.

93. Salser SJ, Loer CM, Kenyon C: Multiple HOM-C gene interactions specify cell fates in the nematode central nervous system. Genes \& Dev 1993, 7(9):1714-1724.

94. Eisenmann DM, Kim SK: Protruding vulva mutants identify novel loci and Wnt signaling factors that function during Caenorhabditis elegans vulva development. Genetics 2000, 156(3):1097-1116.

95. Shemer G, Podbilewicz B: LIN-39/Hox triggers cell division and represses EFF-1/fusogen-dependent vulval cell fusion. Genes \& Dev 2002, 16(24):3136-3141.

96. Tian $\mathrm{H}$, Schlager $\mathrm{B}$, Xiao H, Sommer RJ: Wnt signaling induces vulva development in the nematode Pristionchus pacificus. Curr Biol 2008, 18(2): 142-146

97. Streit A, Kohler R, Marty T, Belfiore M, Takacs-Vellai K, Vigano MA, Schnabel R, Affolter M, Müller F: Conserved Regulation of the
Caenorhabditis elegans labial/Hox1 Gene ceh-13. Dev Biol 2002, 242(2):96-108

98. Aboobaker AA, Blaxter ML: Hox Gene Loss during dynamic evolution of the nematode cluster. Curr Biol 2003, 13:37-40.

99. Chisholm A: Control of cell fate in the tail region of $\mathrm{C}$. elegans by the gene egl-5. Deve 1991, 111(4):921-932.

100. Aboobaker A, Blaxter M: Hox gene evolution in nematodes: novelty conserved. Current Opinion in Genet \& Dev 2003, 13:593-598.

101. Lemons D, McGinnis W: Genomic evolution of Hox gene clusters. Science 2006, 313(5795):1918-1922.

102. Chamberlin HM, Thomas JH: The bromodomain protein LIN-49 and trithorax-related protein LIN-59 affect development and gene expression in Caenorhabditis elegans. Development 2000, 127(4):713-723.

103. Aspöck G, Kagoshima H, Niklaus G, Bürglin TR: Caenorhabditis elegans Has scores of hedgehog related genes: sequence and expression analysis. Genome Res 1999, 9:909-923. genome.cshlp.org.

104. Domazet-Lošo T, Tautz D: A phylogenetically based transcriptome age index mirrors ontogenetic divergence patterns. Nature 2010, 468(7325):815-818.

105. Richardson MK: A phylotypic stage for all animals? Dev Cell 2012, 22(5):903-904.

106. Kalinka AT, Tomancak P: The evolution of early animal embryos: conservation or divergence? Trends In Ecology \& Evolution 2012, 27(7):385-393.

107. De Ley P: A quick tour of nematode diversity and the backbone of nematode phylogeny. In WormBook. Edited by The C. elegans Research Community. WormBook; 2006. http://www.wormbook.org.

108. Martin M: Cutadapt removes adapter sequences from high-throughput sequencing reads. EMBnet.Journal 2011, 17(1).

109. CLCbio: White Paper on de Novo Assembly in CLC Assembly Cell. CLC Bio: Whitepaper; 2010.

110. Kumar S, Blaxter ML: Simultaneous genome sequencing of symbionts and their hosts. Symbiosis 2012, 55(3):119-126.

111. Boetzer M, Henkel CV, Jansen HJ, Butler D, Pirovano W: Scaffolding pre-assembled contigs using SSPACE. Bioinformatics 2011, 27(4):578-579.

112. Smit AFA, Hubley R, Green P: RepeatMasker Open-3.0. 1996-2010. http://www.repeatmasker.org.

113. Jurka J, Kapitonov W, Pavlicek A, Klonowski P, Kohany O, Walichiewicz J: Repbase Update, a database of eukaryotic repetitive elements. Cytogenetic and Genome Res 2005, 110(1-4):462-467.

114. Volfovsky N, Haas BJ, Salzberg SL: A clustering method for repeat analysis in DNA sequences. Genome Biol 2001, 2(8):research0027.1-research0027.11.

115. Bao Z, Eddy SR: Automated de novo identification of repeat sequence families in sequenced genomes. Genome Res 2002, 12(8):1269-1276.

116. Price AL, Jones NC, Pevzner PA: De novo identification of repeat families in large genomes. Bioinformatics 2005, 21 (Suppl 1):i351-i358.

117. Parkinson J, Mitreva M, Whitton C, Thomson M: A transcriptomic analysis of the phylum Nematoda. Nature Genet 2004, 36:1259-1267.

118. Gremme G, Brendel V, Sparks ME, Kurtz S: Engineering a software tool for gene structure prediction in higher organisms. Information and Software Technol 2005, 47(15):965-978.

119. Supek F, Vlahovicek K: INCA: synonymous codon usage analysis and clustering by means of self-organizing map. Bioinformatics 2004, 20(14):2329-2330.

120. Cutter AD, Wasmuth JD, Blaxter ML: The evolution of biased codon and amino acid usage in nematode genomes. Mol Biol Evol 2006, 23(12):2303-2315.

121. Conesa A, Götz S, García-Gómez JM, Terol J, Talón M, Robles M: Blast2GO: a universal tool for annotation, visualization and analysis in functional genomics research. Bioinformatics 2005, 21(18):3674-3676.

122. The Gene Ontology Consortium: Gene Ontology: tool for the unification of biology. Nature Genetics 2000, 25:25-29.

123. Quevillon E, Silventoinen V, Pillai S, Harte N, Mulder N, Apweiler R, Lopez R: InterProScan: protein domains identifier. Nucl Acids Res 2005, 33(Web Server):W116-W120. 
124. Griffiths-Jones S, Moxon S, Marshall M, Khanna A, Eddy S, Bateman A: Rfam: annotating non-coding RNAs in complete genomes. NuCl Acids Res 2004, 33(Database issue):D121-D124.

125. Li L, Stoeckert CJ, Roos DS: OrthoMCL: identification of ortholog groups for eukaryotic genomes. Genome Research 2003, 13(9):2178-2189.

126. van Dongen S: A Cluster algorithm for graphs. Report - Information Syst 2000, 10:1-40,

127. van Dongen S: Graph Clustering by Flow Simulation. PhD thesis, University of Utrecht 2000. http://www.wormbook.org.

128. Seydoux G, Fire A: Whole-mount in situ hybridization for the detection of RNA in Caenorhabditis elegans embryos. Methods in cell biology 1995, 48:323-337.

doi:10.1186/1471-2164-14-923

Cite this article as: Schiffer et al:: The genome of Romanomermis culicivorax: revealing fundamental changes in the core developmental genetic toolkit in Nematoda. BMC Genomics 2013 14:923.

Submit your next manuscript to BioMed Central and take full advantage of:

- Convenient online submission

- Thorough peer review

- No space constraints or color figure charges

- Immediate publication on acceptance

- Inclusion in PubMed, CAS, Scopus and Google Scholar

- Research which is freely available for redistribution

Submit your manuscript at www.biomedcentral.com/submit
C Biomed Central 